\title{
Palliative care for older people: the psychiatrist's role
}

\author{
Victor M. Aziz \& Rugiyya Saeed
}

\begin{abstract}
SUMMARY
In this overview we discuss the palliative psychiatric care of older people towards the end of life. We briefly consider ethics, dementia care, delirium, depression, anxiety, grief and physicianassisted suicide. We also discuss hope, dignity, spirituality and existentialism. We hope that this article will encourage clinicians to reflect on the effects of terminal illnesses on the mental health of dying people and the current provision of palliative psychiatric care.
\end{abstract}

\section{LEARNING OBJECTIVES}

- Appreciate that patient-centred care builds on providing individualised care for the dying person to meet their needs and wishes

- Understand the collaborative role of psychiatry in assessing the aetiology and appropriate response to patients presenting with problems of loss, grief, anxiety, depression, hopelessness, suicidal ideation, personality change and confusion

- Recognise that maintaining hope and living with hope is a way for terminally ill patients to endure and cope with their suffering

\section{DECLARATION OF INTEREST}

None.

\section{Keywords}

Palliative; end of life care; older people; old age psychiatry.

Palliative care is an approach used to improve the quality of life of people facing a terminal illness. It aims to prevent or relieve suffering by identifying and managing pain and other physical, psychosocial and spiritual problems encountered at the end of life (World Health Organization 2018). The National Institute for Health and Care Excellence (NICE 2017) notes the priorities of palliative care to be sensitive communication, patient involvement, addressing the needs of families, an individualised care plan and the recognition of anticipated death. Hence, palliative care is an important part of endof-life care.

In its guidance on treatment and care towards the end of life, the General Medical Council (GMC) states that 'For the purposes of this guidance, patients are "approaching the end of life" when they are likely to die within the next 12 months' (General Medical Council 2010: p. 8). According to the National Institute on Aging, end-of-life care encompasses the care provided during the period approaching death, and in many older people with chronic illnesses, this support might be provided for weeks and even months (National Institute on Aging 2017). A literature review of various perspectives (patient, family, healthcare provider) on what it means to have a good death (Meier 2016) identified a number of core themes, including preferences for a specific dying process, pain-free status, treatment preferences, family, emotional well-being, dignity, spirituality and relationships with healthcare professionals.

Psychiatrists are well positioned to collaboratively assess the aetiology and appropriate response to patients' feelings of loss, grief, anxiety, depression, hopelessness, suicidal ideation, personality change and confusion in palliative care. Early detection and successful treatment of such psychiatric disorders will improve the quality of end-of-life care. Psychiatrists can also provide assessment in the 'grey area' of capacity evaluation, when a patient's cognitive or emotional abilities to make medical and other decisions are in question. Psychotherapeutic and mediation skills can help patients' families (and care providers) when the stress of approaching death triggers unusual conflict (Meier 2016). Old age psychiatrists are particularly skilled in dealing with the uncertainty of prognosis and the difficulty of palliative treatment in individuals with advanced dementia. Box 1 summarises when multidisciplinary professionals should refer to a psychiatrist.

Within the constraints of this article we can offer only an overview of some of the key clinical issues in this area, but at least we hope to raise awareness of such an important topic.

\section{Ethics in palliative care}

The 'four principles' (autonomy, beneficence, nonmaleficence and justice), originally devised by Beauchamp \& Childress (1994), are considered by many to be the standard framework of biomedical
Victor Aziz is a consultant old age psychiatrist with Cwm Taf University Health Board and regional advisor for Wales. Rugiyya Saeed is a higher specialist trainee (ST4) in old age psychiatry in the Wales Deanery. Correspondence Dr V. M. Aziz, OPCMHT, Cynon Valley Hospital, Cwm Taf University Health Board, Mountain Ash, Wales CF45 4DG, UK. Email: victoraziz@doctors.org.uk

\section{Copyright and usage}

(C) The Royal College of Psychiatrists 2018 
BOX 1 When to refer to mental health professionals

The patient should be referred to mental health professionals if there are any of the following:

- diagnostic uncertainty

- other significant psychiatric comorbidities

- suicidal ideation

- requests for doctor-assisted dying

- psychosis

- unresponsiveness to or intolerance of initial trials of psychotropic medication and psychotherapy referral

ethics. It would be unrealistic to present here all the ethical questions that can arise in palliative care, many of which relate to withholding or withdrawing treatment, and we restrict our discussion to the following: disclosure of diagnosis in dementia; antipsychotics and covert medication; the use of restraint; and autonomy and capacity.

\section{Disclosure of diagnosis in dementia}

Dementia is an illness that is frequently encountered in old age psychiatry. It comes hand in hand with several ethical challenges, given its progressive and life-limiting nature. One of the first hurdles is disclosure of this diagnosis. There is no consensus regarding truth telling and dementia. A paternalistic view is that there is little to gain from informing patients that they have a progressive disease such as dementia, and a diagnosis of dementia is likely to cause them distress, which raises dilemmas with the principle of non-maleficence. The Mental Health Foundation's inquiry Truth and Lying in Dementia Care (Kirtley 2016) reported that $98 \%$ of professional carers disclosed using untruths about diagnoses and prognoses on a regular basis. The inquiry agreed on the importance of 'truth-telling' and that most clinicians want to reveal the diagnosis and most patients prefer to know it.

In 2015, the UK's Supreme Court judgment in Montgomery $v$ Lanarkshire Health Board (Lee 2016) caused a change in the law concerning the duty of doctors to disclose information to patients regarding risks. In light of the Montgomery case, disclosure is now based on individual assessment of what the patient might wish to know: 'The test of materiality is whether [...] a reasonable person in the patient's position would be likely to attach significance to the risk, or the doctor is or should reasonably be aware that the particular patient would be likely to attach significance to it'. However, the traditional Bolam principle may still apply in most cases, i.e. a doctor 'is not guilty of negligence if he has acted in accordance with a practice accepted as proper by a responsible body of medical men skilled in that particular art' (Bolam v Friern Health Management Committee [1957]). The concern here is over intrusive legislation in clinical decision-making.

\section{Antipsychotics and covert medication}

Another controversial matter in dementia care is the prescribing of psychotropic agents such as antipsychotic medication. On the one hand, antipsychotics can cause harm as they have side-effects, which means taking the principle of non-maleficence and justice into account. On the other, they can improve quality of life, which upholds the principle of beneficence and increases autonomy. Providing the patient with a good explanation and justification for the care offered is essential in such cases.

Often, covert administration of medication in food or drink is used in the care of patients with dementia who lack capacity and refuse to take it. This can be considered from different viewpoints: those of the treating psychiatrist, the patient, their caregivers, ethicists and the law. It is really important that psychiatrists provide good-quality care that is designed to avoid harm (and harm includes distress) to those who suffer from dementia and other life-limiting illnesses. Treloar et al (2000) believe that autonomy and duty of care are the main ethical principles of relevance here. In a discussion of the ethical and practical issues of covert treatment in psychiatry Singh (2008) concluded that it is 'is seldom needed or justified', but it is essential when the medication is needed for the welfare of the patient and it is the only option available to tide over a crisis. He warns that clinicians should be alert to the chances of malevolence inherent in such a process and should take due precautions to ensure that they do not 'land into legal tangles later'. It is therefore important that the medication reduces the patient's distress and that the decision to administer it covertly is in their best interests, is made only after consultation with all relevant parties and is clearly documented. Haw \& Stubbs (2010) reviewed the literature on covert administration of medicines to older people and reported poor documentation and consultation with relevant parties. They recommended staff education and training to improve standards and safeguard vulnerable patients in institutions. Careful communication with the patient and their family, sometimes with second opinion from a consultant colleague or ethics committee review, may help decision-making. On rare occasions these decisions are reached in the courts. In England and Wales, the Mental Capacity Act 2005 covers 
the care of incapacitous patients; the corresponding legislation in Scotland (Mental Welfare Commission for Scotland 2014) is the Adults with Incapacity (Scotland) Act 2000, and in Northern Ireland it is the Mental Capacity Act (Northern Ireland) 2016.

\section{Use of restraint}

During the different stages of dementia, patients receiving palliative care may present with behavioural problems. Using restraint to administer medication to manage agitation may be distressing and cause psychological harm to the patient, but the principle of beneficence warrants an intervention to reduce the patient's immediate distress. Medical ethics requires a balanced approach, using the least restrictive means to help the patient while being mindful of their autonomy.

\section{Autonomy and capacity}

Clinicians must respect the autonomy of patients who have made advanced care decisions while they still had capacity to do so. Decision-making capacity is a flexible concept that depends on current mental ability, the medical decision in question, and both the complexity and gravity of any possible consequences. Capacity can exist despite memory impairment, provided that the decision-making process remains intact through consistent reasoning and understanding. If a patient refuses treatment or does not wish the family involved in their care, this decision must be respected if they are deemed to have capacity when arriving at it, even if it is not in their best interests. Whatever the outcome, clinicians are required to offer revisions of care and effective care that is appropriate and not excessively burdensome.

\section{Palliative care for people with dementia}

In this section, we discuss some specific issues in dementia care in greater detail.

Owing to the progressive nature of dementia, palliative care plays a crucial role in its management. The palliative approach starts from disclosure of diagnosis, which allows patients to take an active role in managing their illness and enhances a sense of self-efficacy. Clinicians should discuss prognosis, goals of care and completion of advance directives with patients and their families, and formulate a plan for end-of-life care in partnership with patients, families and caregivers. They should be prepared to manage common symptoms, including pain, malnutrition and delirium, using the palliative approach (Husebo 2011; Merel 2014). Heyland et al (2009) surveyed 440 patients and 160 family members to examine the relationship between discussing prognosis with patients and their satisfaction with end- of-life care. They found that focused discussion on quality of life or functional status allowed for adequate information exchange and time to prepare for death, could facilitate advance care planning and improve satisfaction with care. It is important to ensure good-quality discussion as early as possible and to respect the patient's wishes if they do not want to know the prognosis.

\section{Identifying advanced dementia}

The challenges of delivering effective palliative care to older people with dementia include difficulties in diagnosing the terminal phase of the illness, problems relating to communication and medical intervention, and the appropriateness of palliative interventions. As the progression of dementia is often slow and subtle it may be difficult to identify when a patient has reached the advanced stage. The Gold Standards Framework (GSF) prognostic indicator guidance (Gold Standards Framework 2011; Wion 2016) lists a number of criteria that identify advanced dementia, such as inability to carry out activities of daily living, inability to walk without assistance, and urinary and faecal incontinence. The guidance aims to help professionals identify patients nearing the end of their life earlier, which can allow clarification of their particular needs, facilitate discussion of advance care planning, prevent crisis admissions and give them support to 'live well until they die'.

The GSF identifies three triggers that suggest a patient is nearing the end of life:

- the 'surprise question' - 'Would you be surprised if this patient were to die in the next few months, weeks, days?'

- general signs of decline, such as increasing needs or the wish for no further active care

- specific clinical indicators related to certain conditions.

There are two limitations to this framework. First, the 'surprise question' is an intuitive one and often fails as people simply do not recognise that the person is dying. Second, the broader criteria of the GSF include things like low serum albumin and progressive weight loss, which again are of limited use for psychiatrists.

International experts and the European Association for Palliative Care (van der Steen 2014) have developed a framework providing guidance for clinical practice, policy and research of palliative care in dementia. The highest expert ratings on care and research priorities were for person-centred care; communication and shared decision-making; and optimal treatment of symptoms and providing comfort. Other important areas include setting 
care goals and advance care planning; continuity of care; psychosocial and spiritual support; and family care and involvement.

A study by Mitchell et al (2004) found that people dying with advanced dementia in nursing homes were older, had greater functional impairment and more behavioural problems than those who were receiving home care. Also, increasing the provision of dementia training and the range of therapeutic interventions available is essential in care home settings (Centre for Policy on Ageing 2017). The ability to properly assess the patient-caregiver dyad in palliative care for dementia is critical to reducing the negative physical and psychological health outcomes of the illness (Etlers 2008).

\section{Distress and pain}

The most common symptom in people with advanced dementia is distress, which can be due to mental or physical pain, and appropriate treatment is important. There are many possible underlying causes of distress in dementia (Box 2) and a good differential diagnosis is essential so that treatment can be aimed at the most likely cause. Mental distress is as important as physical pain (or perhaps more important), and palliation is needs-based. Alleviation of distress is not just about end-of-life care - its aim is to enable the patient to live as well as possible as they are dying.

Studies have shown that older people with dementia have higher rates of undiagnosed pain, are prescribed less pain-relieving medication and are less likely to receive other treatments such as physiotherapy than older people without the disorder (McAuliffe 2012).

Pain assessment in dementia remains challenging owing to the complexity and individualisation of pain-related behaviours. Someone with dementia may be unable to tell clinicians about the pain they are experiencing, for example they might not be

BOX 2 Potential underlying causes of severe distress in dementia

- Depression

- Psychosis

- Pain

- Poor understanding

- Fear and anxiety

- Insomnia

- Hunger and diet

- Boredom, isolation and lack of spiritual care

- Poor environment, including poor staff practices able to find the right words. Instead, they may express their pain indirectly, perhaps by shouting out, curling up in a ball, pushing carers away, denying that they are experiencing pain or displaying behaviour that challenges.

There is limited evidence on assessing pain in people with advanced dementia in acute settings and currently there is no consensus on how to do so. Hølen et al (2007) evaluated the Doloplus-2 observational pain assessment tool with cognitively impaired elderly people. They reported that it was difficult to conduct the study in people with cognitive impairment and that the tool requires specific administration skills. This study, among others, acknowledges the increasing recognition of the need to use pain assessment tools (Lichtner 2014; Milner 2017). Appropriate training, workforce stability and a standardised approach to pain assessment are key to the successful management of pain in older people with dementia (Burns 2015). The mnemonic PAIN - pick up on mood, assess verbal cues, inspect facial expression, and notice body language - can be helpful (Herr 2006). Van der Steen et al (2015) suggest that a score of 2 or more on the Pain Assessment in Advanced Dementia (PAINAD) scale is an indicator of probable pain and a cut-off value of 2 should serve as a trigger for a trial of pain treatment in this patient group. They also call for the development of tools with sensitivity and specificity in detecting and discriminating pain from other sources of discomfort.

When managing physical pain and other forms of severe distress, the underlying cause should be identified and addressed. It can be difficult to establish the cause of pain in someone who is not able to say where and how they are experiencing it. Staff and carers can check for common causes such as teeth/dentures, a urinary tract infection, ill-fitting footwear, arthritis and constipation. Nonpharmacological approaches to pain relief, such as distraction, applying heat and changing position, are as important as medication. If analgesic medication is given, the World Health Organization's 'analgesia ladder' should be followed, giving consideration to the best route of administration and side-effects (WHO 2017).

\section{Feeding}

As dementia progresses, most people develop problems with feeding. Some become restless during meals, or they simply forget to eat or how to eat. Interventions to facilitate nutrition can include eating meals with caregivers, longer mealtimes, education and support for caregivers, multisensory exercise and multicomponent interventions. Assistance with eating can include feeding by hand, offering 
meals with extra calories, and encouraging the person to eat. In very advanced dementia and close to the end of life, some people can no longer swallow, and other means of feeding should be discussed with the family as the clinical need arises ( $\mathrm{Ng} 2016)$.

\section{'Do not resuscitate' decisions}

In caring for older people, clinicians often have to make the 'do not resuscitate' (DNR, or 'do not attempt resuscitation', DNAR) decision, pertaining to the appropriateness of attempting resuscitation following a cardiac arrest. A systematic review of the literature investigated the relationship between age and DNR orders. The authors found that these were more prevalent for older patients and this was independent of other mediating factors such as illness severity and likely outcome. They concluded that the patient's age increases the use of DNR orders (Cook 2017).

\section{Medication review}

In palliative care, it is important to review all medications and discontinue any that are no longer beneficial. There is insufficient evidence on when to discontinue acetylcholinesterase inhibitors in dementia, but there are anecdotal reports of rapid decline in function, withdrawal symptoms and paralytic ileus with abrupt withdrawal. If discontinuation is considered, a gradual withdrawal should be pursued.

\section{Better care}

Better palliative care for people with a dementia (Fox 2017) should consider the severity of the dementia, any comorbid severe distress (mental or physical) that is not easily amenable to treatment, severe physical frailty and any comorbid cancer that merits palliative care services in its own right. Interdisciplinary full assessment of needs, a focused analysis of the cause of distress, and exploring ways to improve these symptoms and reduce the distress are essential.

\section{Delirium}

Delirium is a common complication encountered during palliative care. It affects a patient's ability to communicate, make decisions and function, and is associated with increased mortality. It is distressing to the families of those affected, especially if patients become agitated or aggressive. Hypoactive delirium is an important consideration in the final days of life (Spiller 2006). Hey et al (2015) reported that symptoms suggestive of delirium were managed in $56.3 \%$ of cases in a hospital, compared with 66.7 and $72.2 \%$ in two hospices. The definitive use of the term as a diagnosis was associated with clearer management plans in the hospital patients.

\section{Management of symptoms}

There is no evidence that cholinesterase inhibitors are of benefit in the management of acute delirium. Similarly, there is a paucity of evidence of benefit from clinically assisted hydration in patients with terminal delirium. Good practice would suggest that medication may be required if verbal and nonverbal de-escalation techniques are not appropriate or have not resolved symptoms (Candy 2012a).

A clinical and ethical problem in delirium management in older people is the use of both antipsychotics and benzodiazepines. Fong et al (2009) reviewed delirium in elderly people and reported that medications to treat behavioural changes in delirium may further cloud the patient's mental mind and should therefore be avoided if possible. Antipsychotics (such as haloperidol, risperidone, olanzapine and quetiapine) reduced the severity and duration of delirium and length of hospital stay in some patients without causing notable adverse effects. However, antipsychotics carry an increased risk of stroke in elderly patients with dementia and can result in prolongation of the QT interval. The authors also recommended that benzodiazepines are not used as first-line agents in the treatment of delirium, because they often exacerbate mental status changes and cause over-sedation. A meta-analysis by Neufeld et al (2016) found no improvement in outcomes with antipsychotics in either prevention or treatment of delirium. NICE (2010) supports the short-term use of antipsychotic medication in patients with significant distress due to delirium, who may be at risk of harm to self or others, or whose symptoms interfere with treatment of the underlying cause, and when non-pharmacological interventions have failed.

Overall, any reversible causes should be identified and treated appropriately. Good management includes giving explanations and reassurance in a calming environment, involving family and carers to support with reorientation, and addressing any sensory impairment. A review of all medication is essential. For instance, drugs with anticholinergic effects may cause or worsen delirium in patients with dementia. Explanation to the family is also essential.

\section{Grief, anxiety and depression}

When a patient is approaching the end of life, clinicians should acknowledge the person's sense of loss and the associated grief, actively listen and explore their concerns, reinforce their strength in coping 
with their illness and facilitate communication with loved ones.

A meta-analysis by Mitchell et al (2011) assessed the prevalence of depression, anxiety and adjustment disorders in oncological, haematological and palliative care settings. The pooled prevalence of depression was $16.5 \%$, adjustment disorder $15.4 \%$ and anxiety disorders 9.8\%. The authors advised clinicians to be vigilant for mood complications and not just depression, especially since a combination of mood disorders occurred in 30-40\% of patients, without a significant difference between the three settings.

Adjustment disorder, major depression and anxiety disorders occur in between 10 and 34\% of patients with cancer. The reported prevalence of anxiety disorders in terminally ill patients with cancer or AIDS ranges from 6 to 49\%, with some studies indicating a higher prevalence of mixed anxiety and depressive symptoms in cancer patients (Payne 2000; Lloyd-Williams 2008). Anxiety may include fears about the disease process, the clinical course, possible treatment outcomes, social stigma and death (Ford 2016).

Depression is commonly encountered in palliative care patients and is associated with morbidity and distress. Depressive symptoms are present in 15$50 \%$ of patients with cancer and 5-20\% will meet diagnostic criteria for major depressive disorder (Massie 2004). Dying patients may experience a broad spectrum of depressive symptoms, ranging from transient sadness, demoralisation and adjustment disorder to pathological grief and psychotic depression (see Box 3 for an example of a fictitious case). Patients may underreport or consciously

BOX 3 Case vignette: illness-related psychotic depression

A 70-year-old man had been physically healthy and socially active until he had a road traffic accident on his motorbike. He was later diagnosed with prostate cancer that was successfully treated by the oncology team. Unfortunately, he was subsequently diagnosed with bladder cancer and developed depressive symptoms with a somatic delusion that his throat was blocked and he was unable to swallow. He was therefore not eating or drinking, which has led to significant weight loss. He also started to refuse his bladder cancer treatment, which led to a referral to a psychiatry service for older people. He was admitted to hospital, where he was diagnosed with psychotic depression and received ECT (following the failure of treatment with two antidepressants and an antipsychotic). With multidisciplinary input, including psychotherapy, his ability to engage with cancer treatment improved and his depression lifted. disguise depressive symptoms in their final weeks of life (Hinton 1994).

Clinicians need to be aware of diagnostic challenges such as the neurovegetative symptoms of depression: anergia, fatigue, weight loss, anorexia, impaired concentration and sleep disturbances are also common manifestations of advanced medical illness. Clinicians may believe that the patient's depression is an appropriate response to the dying process. A Japanese study (Okajima 2015) reported that many psychiatrists are unfamiliar with denial or the desire for a hastened death among dying patients and are puzzled by how psychological phenomena may be indistinguishable from physical symptoms at the end of life. They also found that changes in the diagnostic criteria for 'depression due to grief' and difficulties in diagnosis could lead to therapeutic predicaments, and that depression at the end of life is difficult to treat because antidepressant medications are often not effective at this stage.

Depression, pain, debility, hopelessness and a sense of being burden to others have been identified as key risk factors for suicidal behaviour (Abbey 2006; Park 2016). The clinician's role is to identify suicidality and perform a thorough suicide risk assessment. For a discussion of suicide interventions and prevention strategies in older people, we recommend a review article by Kiriakidis (2015).

Various individualised psychotherapeutic interventions have been shown to improve outcomes among cancer patients with depression. These include dignity therapy, discussing goals of building bonds, refining life's priorities, 'detoxifying' the experience of death and dying, supportiveexpressive group therapy, depression education, problem-solving and coping techniques (Marks 2013).

On the other hand, the improved risk-benefit ratio of selective serotonin reuptake inhibitors and serotonin-noradrenaline reuptake inhibitors makes it important to recognise and treat depressive symptoms (Sanjida 2016).

\section{Doctor/physician-assisted suicide}

Assisted suicide is the act of intentionally killing oneself with the aid of someone who provides the knowledge or the means to do so. Despite ethical prohibitions, public interest in doctor-assisted suicide has grown in recent years. From the patient's point of view, it raises the question of autonomy ('It's my life'). However, many clinicians believe that it violates the fundamental tenet of medicine as it is incompatible with the doctor's role as a healer.

In a recent debate in the $B M J$ about whether doctor-assisted dying should be legal or not (English 2018), the authors clarified that assisted 
dying does not include euthanasia or assisted suicide. The GMC's guidance relating to assisting suicide (General Medical Council 2013) notes that respect for a patient's autonomy cannot justify illegal action and it is a criminal offence for anyone to encourage or assist a person to commit or attempt suicide. It is of note that in 2015, members of parliament in the House of Commons voted overwhelmingly against Lord Falconer's Assisted Dying Bill of 2014 and changing the law to allow doctors to help terminally ill people end their lives (Dignity in Dying 2015).

The American College of Physicians (ACP) (Snyder 2017) believes that the ethical arguments against legalising doctor-assisted suicide remain the most compelling. The ACP recognises the effect that it could have on the trusting relationship between the patient and the doctor and on the medical profession's role in society.

\section{Hopelessness}

Hope is a concept that suggests a greater emotional component than mere expectation and it is seen as an active process of conscious and unconscious meaning. Several studies among patients with advanced terminal illness have shown that severe or pervasive hopelessness tends to be confined to those who are depressed or have expressed a genuine desire for early death. In a study involving 92 in-patients with terminal cancer in which 17\% had a high desire for hastened death and 16\% met the criteria for a current major depressive disorder, desire for hastened death was significantly associated with clinical depression and hopelessness (Breitbart 2000). Maintaining hope and living with hope is a way for terminally ill patients to endure and cope with their suffering. Hence, identifying and addressing hopelessness forms an important aspect of palliative care.

Resilience has been significantly associated with less hopelessness and higher levels of perceived social support (Somasundaram 2016). Clinicians who can recover from, resist or adapt to the physical and psychological demands of caring can be considered 'resilient'. Resilience interventions may include: burnout education, work-life balance, and adjustment of one's relationship to work, mindfulness practice, and acceptance of the clinical work environment (Hlubocky 2017).

\section{Dignity}

Some people experience the inability to maintain independence while dying as a fundamental loss of dignity, undermining the value of life itself (Pullman 2002). If 'dignity' is understood to mean 'deserving of honour, respect or esteem', its conceptual overlap with burden to others suggests a self-perception wherein patients no longer consider themselves worthy of these attributes.

Patients with significant dignity-related concerns have reported increased pain, decreased quality of life, difficulty with bowel functioning and dependence on others for self-care. They also reported a loss of will to live, increased desire for death, depression, hopelessness and anxiety (Chochinov 2002a). Studies suggest that listening to patients, validating their concerns and ascribing meaning to their experience may engender hope and ultimately bolster dignity towards the end of life.

The dignity-conserving model of care (Chochinov 2002b) consists of three major categories: illnessrelated concerns that impinge on the patient's sense of dignity; a dignity-conserving repertoire pertaining to the patient's psychological make-up and spiritual beliefs; and a social dignity inventory, referring to external factors (e.g. privacy, tenor of care, fear of being a burden) that affect dignity. The dignity model can guide clinicians to find interventional strategies in end-of-life care.

\section{Spirituality and existentialism}

In palliative care, it is imperative that the individualised approach adopted for each person explores and respects that person's cultural, religious and spiritual needs. These will be key factors in how they live their life, but also may influence the decisions they make about their clinical care (Candy 2012b). NICE quality markers for end-of-life care for adults require that "people approaching the end of life are offered spiritual and religious support appropriate to their needs and preferences' (NICE 2011: p. 35).

In secular societies, explicit or implicit religious connotations associated with spirituality have been moderated such that many make no mention of God or a higher power. Instead, the word evokes a sense of searching or yearning for significance or meaning in life. Spiritual suffering or pain may manifest itself in physical (intractable pain), psychological (anxiety, depression), religious (crisis of faith) or social (disintegration of human relationships) ways (Handzo 2011).

Patients who experience spiritual pain can be desperate to escape their situation and may have unrealistic expectations, such as continuing to try therapies in the absence of any benefit, and may demand escalating doses of analgesics and sedatives despite no apparent benefit. McClain et al (2003) concluded that spiritual well-being offers some protection against end-of-life despair, on the basis of their finding that depression was significantly 
MCO answers

$1 \mathrm{a} \quad 2 \mathrm{e} \quad 3 \mathrm{~b} \quad 4 \mathrm{~d} \quad 5 \mathrm{c}$ correlated with desire for hastened death in patients low in spiritual well-being.

According to Boston et al (2011) 'existential suffering and deep personal anguish at the end of life are some of the most debilitating conditions that occur in patients who are dying'. A psychotherapeutic orientation based on existential philosophy views serious illness as an opportunity for growth. Confronted with the prospect of annihilation, patients' life-time assumptions about meaning and value may be shattered by their daily illness experience and this affords them an opportunity to re-evaluate life activities and to choose those that add greatest meaning, purpose and value in the time left (Spira 2000).

Given the broad range of definitions attributed to existential suffering, palliative care clinicians may need to be mindful of their own choices and consider treatment options from a critical perspective.

\section{Conclusions}

It is important that healthcare services improve palliative care provisions for older people, especially those with advanced dementia. They need to overcome the culture of 'death phobia' and encourage successful ageing and successful dying. Mental health professionals should raise the subject of end-of-life care with all older people as early as possible. When a patient dies, their teams should reflect on and discuss their own experiences of death. There is also a need for teams to reflect on people dying within hospital, community and care home settings. In all care settings, teams should consider the effect a death may have on other residents or patients, particularly in psychiatric units.

There is also a need to develop measurement tools to examine how specific diseases and interventions are most important to patients nearing the end of their lives including those with dementia. In particular, we support the recommendations for future research that was discussed in the Fox et al paper (Fox 2017).

\section{References}

Abbey JG, Rosenfeld B, Pessin H, et al (2006) Hopelessness at the end of life: the utility of the hopelessness scale with terminally ill cancer patients. British Journal of Health Psychology, 11: 173-83.

Beauchamp TL, Childress JF (1994) Principles of Biomedical Ethics (4th edn). Oxford University Press.

Bolam v Friern Hospital Management Committee [1957] 1 WLR 582 (QB).

Boston P, Bruce A, Schreiber R (2011) Existential suffering in the palliative care setting: an integrated literature review. Journal of Pain and Symptom Management, 41: 604-18.

Breitbart E, Rosenfeld B, Pessin H, et al (2000) Depression, hopelessness and desire for hastened death in terminally ill patients with cancer. JAMA, 284: 2907-11.
Burns M, Mcllfatrick S (2015) Palliative care in dementia: literature review of nurses' knowledge and attitudes towards pain assessment. International Journal of Palliative Nursing, 21: 400-7.

Candy B, Jackson KC, Jones L, et al (2012a) Drug therapy for delirium in terminally ill adult patients. Cochrane Database of Systematic Reviews, 11: CD004770 (doi: 10.1002/14651858.CD004770.pub2).

Candy B, Jones L, Varagunam M, et al (2012b) Spiritual and religious interventions for well-being of adults in the terminal phase of disease. Cochrane Database of Systematic Reviews, 5: CD007544 (doi: 10.1002/ 14651858.CD007544.pub2).

Centre for Policy on Ageing (2017) The Assessment and Management of Pain in Older People. Centre for Policy on Ageing (http://www.cpa.org.uk/ information/readings/pain.pdf).

Chochinov HM, Hack T, Hassard T, et al (2002a) Dignity in the terminally ill: a cross-sectional, cohort study. Lancet, 360: 2026-30.

Chochinov HM (2002b) Dignity-conserving care - a new model for palliative care: : helping the patient feel valued. JAMA, 287: 2253-60.

Cook I, Kirkup AL, Langham LJ, et al (2017) End of life care and do not resuscitate orders: how much does age influence decision making? A systematic review and meta-analysis. Gerontology \& Geriatric Medicine, 3 : $1-17$.

Dignity in Dying (2015) Lord Falconer's Assisted Dying Bill (2014). Dignity in Dying (https://www.dignityindying.org.uk/assisted-dying/the-law/lordfalconers-assisted-dying-bill-2014/). Accessed 1 July 2018.

English T, Ribeiro B (2018) Should doctor assisted dying be legal? BMJ, 360: k562.

Etlers L, Goodall D, Harrison BE (2008) Caregiver burden among dementia patient caregivers; a review of the literatures. Journal of the American Academy of Nurse Practitioners, 20: 423-81.

Fong TG, Tulebaev SR, Inouye SK (2009) Delirium in elderly adults: diagnosis, prevention and treatment. Nature Reviews, Neurology, 5: 210-20.

Ford JA (2016) The complexity of assessment and treatment for anxiety in patients with a terminal illness. Journal of Hospice and Palliative Nursing, 18: 131-8.

Fox S, FitzGerald C, Harrison Dening K, et al (2017) Better palliative care for people with a dementia: summary of interdisciplinary workshop highlighting current gaps and recommendations for future research. BMC Palliative Care, 17, 9.

General Medical Council (2010) Treatment and Care towards the End of Life: Good Practice in Decision Making. GMC

General Medical Council (2013) Guidance Relating to Assisting Suicide. GMC (https://www.gmc-uk.org/guidance/news_consultation/14344.asp). Accessed 16 May 2018.

Gold Standards Framework Team (2016) The Gold Standards Framework Proactive Identification Guidance (PIG) (6th edn). Gold Standards Framework (http://www.goldstandardsframework.org.uk/PIG). Accessed 1 July 2018

Handzo G (2011) Spiritual care for palliative patients. Current Problems in Cancer, 35: 365-71

Haw C, Stubbs J (2010) Covert administration of medication to older adults: a review of the literature and published studies. Journal of Psychiatric and Mental Health Nursing, 17: 761-68.

Herr K, Bjoro K, Docker S (2006) Tools for assessment of pain in nonverbal older adults with dementia. A state-of-the science review. Journal of Pain and Symptom Management, 31: 170-192.

Hey J, Hosker C, Ward J, et al (2015) Delirium in palliative care: detection, documentation and management in three settings. Palliative \& Supportive Care, 13: 1541-5

Heyland DK, Allan DE, Rocker G, et al (2009) Discussing prognosis with patients and their families near the end of life: impact on satisfaction with end-of-life care. Open Medicine, 3: e101-10.

Hinton J (1994) Can home care maintain an acceptable quality of life for patients with terminal cancer and their relatives? Palliative Medicine, 8 : 183-96. 
Hlubocky FJ, Rose M, Epstein RM (2017) Mastering resilience in oncology: learn to thrive in the face of burnout. American Society of Clinical Oncology Educational Book, 37: 771-81.

Hølen JC, Saltvedt I, Fayers PM, et al (2007) Doloplus-2, a valid tool for behavioural pain assessment? BMC Geriatrics, 7: 29.

Husebo BS, Ballard C, Sandvik R, et al (2011) Efficacy of treating pain to reduce behavioural disturbances in residents of nursing homes with dementia: cluster randomised clinical trial. BMJ, 343 : d4065.

Kiriakidis SP (2015) Elderly suicide: risk factors and preventive strategies. Annals of Gerontology and Geriatric Research, 2: 1028.

Kirtley A, Williamson T (2016) What is Truth? An Inquiry about Truth and Lying in Dementia Care. Mental Health Foundation.

Lee A (2016) 'Bolam' to 'Montgomery' is Result of Evolutionary Change of Medical Practice Towards 'Patient-Centred Care'. Postgraduate Medical Journal, 93: 46-50.

Lichtner V, Dowding D, Esterhuizen P, et al (2014) Pain assessment for people with dementia: a systematic review of systematic reviews of pain assessment tools. BMC Geriatrics, 14: 138.

Lloyd-Williams M, Hughes JG (2008) The management of anxiety in advanced disease. Progress in Palliative Care, 16: 47-50.

Marks S, Heinrich T (2013) Assessing and treating depression in palliative care patients. Current Psychiatry, 12(8): 35-40.

Massie MJ (2004) Prevalence of depression in patients with cancer. Journal of the National Cancer Institute: Monographs, 32: 57-71.

McAuliffe L, Brown D, Fetherstonhaugh D (2012) Pain and dementia: an overview of the literature. International Journal of Older People Nursing, 7: 219-22

McClain CS, Rosenfeld B, Breitbart W (2003) Effect of spiritual wellbeing on end-of-life despair in terminally-ill cancer patients. Lancet, 361: $1603-7$

Mental Welfare Commission for Scotland (2014) Good Practice Guide: Covert Medication. Mental Welfare Commission for Scotland (https://www.mwcscot.org.uk/media/140485/covert_medication_finalnov_13.pdf).

Meier EA, Gallegos JV, Montross Thomas LP, et al (2016) Defining a good death (successful dying): literature review and a call for research and public dialogue. American Journal of Geriatric Psychiatry, 24: 261-71.

Merel S, DeMers S, Vig E (2014) Palliative care in advanced dementia. Clinics in Geriatric Medicine, 30: 469-92.

Milner S (2017) How should nurses assess pain in people with advanced dementia? Ageing and Health, 21: 20-4.

Mitchell SL, Morris JN, Park PS, et al (2004) Terminal care for persons with advanced dementia in the nursing home and home care settings. Journal of Palliative Medicine, 7: 808-16.

Mitchell AJ, Chan M, Bhatti H, et al (2011) Prevalence of depression, anxiety, and adjustment disorder in oncological, haematological, and palliative-care settings: a meta-analysis of 94 interview-based studies. Lancet Oncology, 12: 160-74.

National Institute for Health and Care Excellence (2010) Delirium: Prevention, Diagnosis, and Management (Clinical Guideline CG103). NICE.

National Institute for Health and Care Excellence (2011) End of Life Care for Adults (Quality Standard OS144). NICE.

National Institute for Health and Care Excellence (2017) Care of Dying Adults in the Last Days of Life (Quality Standard QS144). NICE.
National Institute on Aging (2017) What Is End-of-Life Care? NIA (https://www.nia.nih.gov/health/what-end-life-care). Accessed 1 July 2018.

Neufeld KJ, Yue J, Robinson TN, et al (2016) Antipsychotics for prevention and treatment of delirium in hospitalized adults: a systematic review and meta-analysis. Journal of the American Geriatrics Society, 64: 705-14.

Ng K, Marchington K, Algu K, et al (2016) Feeding Choices for Patients with Advanced Dementia. University Health Network.

Okajima Y (2015) Why do psychiatrists face difficulties when treating dying patients and their family members? [Article in Japanese], Seishin Shinkeigaku Zasshi, 117: 978-83.

Park SA, Chung SH, Lee Y (2016) Factors associated with suicide risk in advanced cancer patients: a cross-sectional study. Asian Pacific Journal of Cancer Prevention, 17: 4831-6.

Payne DK, Massie MJ (2000) Anxiety in palliative care. In Handbook of Psychiatry in Palliative Medicine (eds HM Chochinov, W Breitbart): 63-74. Oxford University Press.

Pullman D (2002) Human dignity and the ethics and aesthetics of pain and suffering. Theoretical Medicine and Bioethics, 23: 75-94.

Sanjida S, Janda M, Kissane D, et al (2016) A systematic review and meta-analysis of prescribing practices of antidepressants in cancer patients. Psycho-Oncology, 25: 1002-16

Singh AR (2008) Covert treatment in psychiatry: do no harm, true, but also dare to care. Mens Sana Monographs, 6: 81-109.

Snyder SL, Mueller PS (2017) Ethics and the legalization of physicianassisted suicide: an American College of Physicians position paper. Annals of Internal Medicine, 167: 576-8.

Somasundaram RO, Devamani KA (2016) A comparative study on resilience, perceived social support and hopelessness among cancer patients treated with curative and palliative care. Indian Journal of Palliative Care, 22: $135-40$.

Spiller JA, Keen JC (2006) Hypoactive delirium: assessing the extent of the problem for inpatient specialist palliative care. Palliative Medicine, 20: 17-23

Spira JL (2000) Existential psychotherapy in palliative care. In Handbook of Psychiatry in Palliative Medicine (eds HM Chochinov, W Breitbart): 197-214. Oxford University Press.

Treloar A, Beats B, Philpot M (2000) A pill in the sandwich: covert medication in food and drink. Journal of the Royal Society of Medicine, 93 : 408-11.

van der Steen JT, Radbruch L, Hertogh CM, et al (2014) White paper defining optimal palliative care in older people with dementia: a Delphi study and recommendations from the European Association for Palliative Care. Palliative Medicine, 28: 197-209.

van der Steen JT, Sampson EL, Van den Block L, et al (2015) Tools to assess pain or lack of comfort in dementia: a content analysis. Journal of Pain and Symptom Management, 50: 659-75.e3.

Wion RK, Loeb SJ (2016) End-of-life care behind bars: a systematic review. American Journal of Nursing, 116: 24-36.

World Health Organization (2017) WHO's cancer pain ladder for adults. WHO (http://www.who.int/cancer/palliative/painladder/en/). Accessed 16 May 2018.

World Health Organization (2018) WHO Definition of Palliative Care. WHO (http://www.who.int/cancer/palliative/definition/en/). Accessed 1 July 2018. 


\section{MCOs}

Select the single best option for each question stem

1 The role of the psychiatrist in end-of-life care is to:

a detect and treat psychiatric disorder, in order to promote quality in end-of-life care

b discourage referrals from other professionals

c decline educating and practical experience of caring for dying individuals

d frame acceptance of death as an escape from suffering and pain

e promote helplessness while working with dying people.

2 Palliative and end-of-life care for people with dementia includes:

a disclosure of diagnosis

b pain management

c hydration and feeding

d staff training and education

e all of the above.
3 As regards spirituality and existentialism:

a spirituality can evoke a sense of searching or yearning for non-significance meaning in life

b NICE quality markers for end-of-life care require that people are offered spiritual and religious support appropriate to their needs and preferences

c spiritual suffering or pain does not manifest itself in religious or social ways

d existential suffering and deep personal anguish at the end of life are mild conditions that occur in patients who are dying

e psychotherapies based on existential philosophy do not offer any opportunity for growth.

4 As regards dignity in terminal illness:

a the dignity-conserving model consists of four major categories

b dignity can be understood as not deserving honour, respect or esteem

c patients with significant dignity-related concerns report lower levels of pain and better quality of life d listening to patients, validating their concerns and ascribing meaning to their experience may bolster dignity towards the end of life

e the social dignity inventory refers to internal factors that affect dignity.

5 As regards hopelessness and resilience:

a hope is seen as a passive process of conscious and unconscious meaning

b Breitbart et al (2000) reported that $36 \%$ of terminally ill patients met criteria for a current major depressive disorder

c caregivers who are able to recover from, resist or adapt to the physical and psychological demands of caring can be considered 'resilient'

$\mathrm{d}$ attainment of resilience is not a core treatment goal in palliative care

e desire for hastened death has not been associated with hopelessness. 